\title{
Multidrug-Resistant Acinetobacter baumannii Infections in a Cardiovascular Surgery Intensive Care Unit: Risk Factors and Outcome Predictors
}

\author{
Seyhan Yagar $^{1}$ and MINE ÇAVUŞ ${ }^{2}$ \\ ${ }^{1}$ Ministry of Health Ankara City Hospital Cardiovascular Hospital \\ ${ }^{2}$ Ministry of Health Kayseri City Hospital
}

December 16, 2020

\begin{abstract}
Acinetobacter baumannii $(\mathrm{AB})$ is a ubiquitous gram-negative coccobacillus that has the ability to colonize and survive in a variety of environments and develop various resistance mechanisms. In our study; Between 2010 and 2012, 5400 patients were screened, 74 of them had MDR AB infection. MDR AB infection is associated with high morbidity and mortality.
\end{abstract}

Multidrug-Resistant Acinetobacter baumannii Infections in a Cardiovascular Surgery Intensive Care Unit: Risk Factors and Outcome Predictors

Yagar $\mathrm{S}^{1}$, Çavuş $\mathrm{MA}^{2}$

${ }^{1}$ Department of Intensive Care, University of Health Sciences, Ankara City Hospital, Ankara, Turkey

${ }^{2}$ Department of Intensive Care, University of Health Sciences, Kayseri City Hospital, Kayseri, Turkey

Seyhan Yağar, MD

Department of Anestesiology and Reanimation, University of Health Sciences,Ankara City Hospital, Ankara, Turkey

email:seyhanyagar@yahoo.com

Phone: +90 532-4171143

ORCID:0000-0003-1240-7775

Mine Altınkaya Çavus, MD

Department of Intensive Care, University of Health Sciences, Kayseri City Hospital, Kayseri, Turkey

email:minealtinkaya@yahoo.com

Phone: $+90533-7332458$

ORCID: 0000-0003-2584-0463 (corresponding author)

Multidrug-Resistant Acinetobacter baumannii Infections in a Cardiovascular Surgery Intensive Care Unit: Risk Factors and Outcome Predictors

INTRODUCTION 
Infection in the setting of cardiovascular surgery is not infrequent and associated with adverse outcomes and mortality. Multidrug resistant organism related infection cases have augmented in in this setting lately whereas in the other type of ICU's. Acinetobacter baumannii (AB) is a gram-negative coccobasillus, which is a ubiquitous microorganism having ability to colonize and survive in diverse environments and improve diverse mechanisms of resistance, due to $\mathrm{AB}$ is difficult to control in hospitals. [1-6]. Particularly multidrugresistant (MDR)-AB infections (isolate is non-susceptible to at least one agent in three or more antibiotic classes) associated with high mortality rates in intensive care units (ICUs) [3,6,7].

After an MDR-AB infection epidemic in our hospital at the end of 2009 we aimed to search the rate of multidrug-resistant acinetobacter baumannii infections in cardiovascular surgery intensive care unit (CSICU) and risk factors and independent outcome predictors retrospectively for 2 year time period.

\section{MATERIALS AND METHODS}

All necessary ethical approvals for conducting the study have been obtained. This is a retrospective study, conducted in a tertiary cardiac hospital ICU's with 30 beds. We evaluated patients who underwent adult cardiovascular surgeries during the period from March 2010 to February 2012. Cases were defined as new acquisitions of MDR-AB from specimen taken [?]48 hours following ICU admission, with clinical signs of infection. Data on the characteristics, laboratory results, applied treatments were collected from the electronic medical records and patients' charts. The Hospital's Infection Committee managed antibiotic treatment. Recorded data were as follows: age, gender, medical history, SOFA score on the day of infection diagnosis, type of surgery, postoperative days until infection, infection site, antibiotic susceptibility, complications (such as organ dysfunction, thrombocytopenia), days of mechanical ventilation after infection and length of CS-ICU stay.

\section{STATISTICS}

Analysis of the data was performed using SPSS v.17 statistical program (SPSS Inc., Chicago, IL, USA). Continuous variables were presented as mean \pm standard deviation and categorical variables were expressed as number (\%). Comparative analysis was conducted Mann-Whitney U and chi-square tests. Logistic regression analysis was performed to determine the independent risk factors for mortality. p[?] 0.05 is considered as statistically significant differences.

\section{RESULTS}

During the study period, 74 (1.3\%) of 5400 consecutive cardiovascular surgery patients developed MDR-AB infection and consisted our study population. Demographic and clinical data of the patients are presented in Table 1. The mean age of the patients was 64,2 and the mean SOFA score was $11,2+-3,07$. The majority of undergone surgical procedures were 32 coronary artery bypass, 12 coronary artery bypass + valve surgery, 11 bivalvular surgery, and 13 aortic surgery. The lower respiratory tract was the most frequent site $(78.4 \%)$ of MDR-AB isolation and followed by surgical site (10.8\%). Colistin was the most active antimicrobial agent. Univariate analysis for mortality is presented in Table 2. None of the preoperative existing comorbidities was affecting mortality except hypertension, which is found protective. In hypertensive group mortality rate was $61.5 \%$ whereas in non-hypertensive group was $85.4 \%$ (p:0.022). In logistic regression analyse SOFA score, acute renal failure, mechanical ventilation duration, coagulopathy, hypoalbuminemia, inotropic support, acidosis, intensive care hospitalization, elevated glucose value, low lymphocyte count appear as predictors of the mortality.

Mortality rate was $77 \%$ with 57 patients. SOFA score was significantly higher in mortal group 11,54+-2,9 vs $9,41+-1,9$ (p: 0.008). Beside SOFA score low output syndrome, renal replacement therapy requirement, hypoalbuminemia, coagulopathy, hepatic insufficiency, cerebral dysfunction and hyperbilirubinemia were statistically significant predictors for mortality. İn addition, inotrop usage was higher comparing to the survival group. In these patients with significantly lower calculated lymphocyte counts, the association of low lymphocyte levels detected in follow-up with mortality. This may be a poor prognostic factor. While the mean of glucose in the mortal group was high, it was not statistically significant. Whereas acidosis was 
more common in the mortal group.

\section{DISCUSION}

Epidemiological surveillance of bacterial infection and resistance to antibiotics are essential for awareness creation, implementation of control measures and effective management of infections. In developing countries as in Sub-Saharan Africa, insufficient measures to prevent infections caused by multidrug-resistant bacteria cause an increase in mortality and morbidity $[8,9]$. Cardiac surgical patients may show diversity from other surgical and medical ICU patients

The clinical management of intensive care unit (ICU) patients with infections has been complicated by the emergence and spread of extremely drug-resistant (XDR) Acinetobacter baumannii strains [8]. Infections caused by multidrug resistant Acinetobacter baumannii strains; may cause life-threatening poor patient outcomes such as ventilator-related pneumonia, sepsis, urinary tract infections, and skin and soft tissue disorders $[10,11]$. In our study, the infection affected more of the respiratory system $(78.4 \%)$. In decreasing rates; surgical site, blood and urinary system were isolated $\mathrm{AB}$.

The pediatric and geriatric patients are usually more disposed to infections due to their immune status. The advancing age are commonly associated with risk factors including reduced immunity, co-morbid diseases such as chronic heart diseases, diabetes mellitus, neurogenic bladder [12,13] whilst in infants, lack of fully developed immunity, malnutrition as well as inadequate hygiene [14] put them at greater risk of infections. In a study conducted in Ghana, urinary tract infection was 31\% [15].Respiratory system diseases,DM,renal diseases,HL,HT were in our patients risk factors.

MDR A. baumannii is a problematic, multidrug-resistant pathogen identifed in healthcare settings worldwide, especially in ICUs [16]. A. baumannii has a notable ability to capture and express resistance genes. All resistance mechanisms including target modifcation, efux pump expression, and enzymatic inactivation have been described in A. baumannii [17].

A. baumannii is considered as an opportunistic pathogen that can survive in austere conditions. It is responsible of an increasing rate of severe nosocomial infections. They affect especially immunocompromised patients, exposed to prolonged stays in ICUs and having a previous exposure to antibiotics; carbapenems and 3rd generation cephalosporins are the most involved, followed by fluoroquinolones, aminoglycosides and metronidazole $(18,19)$. Other factors that are associated with the occurrence of A. baumannii bacteremia are: assisted ventilation, central catheterization, urinary catheters, and nasogastric probes (20). All the patients included in the study had these risk factors

Katsaragakis et al. (21) investigated the mortality pre-determinants of patients with A. baumannii infection in a prospective study of 680 patients with surgical ICU. This study showed that the APACHE II score is one of the predisposing factors affecting mortality due to A. baumannii infection. Another study by Pirates et al. (22) showed that the APACHE II score is an independent risk factor when considering the mortality of the patients present at the time of an A. baumannii outbreak in the ICU.

In other studies, age, severity of the underlying disease, immunosuppression, recent surgery, mechanical ventilation, septic shock, thrombocytopenia,low serum albumin, multi drug resistance, inappropriate antimicrobial therapy, and invasive procedures such as central venous catheterization, urinary catheterization, nasogastric tube placement, and pulmonary catheterization have been found as factors affectingA baumannii infectionrelatedmortality in univariate analysis $(23,25,26,29,31)$. In multivariate analysis, age, immunosuppression, APACHE II score, multiresistance, mechanical ventilation, recent surgery, septic shock, and respiratory and renal failure have been identified as factors independently correlated with mortality $(23,25,29)$. We have reached similar findings in these studies

Disseminated intravascular coagulation, APACHE II score, inappropriate antimicrobial treatment, and neutropenia have also been reported as predictors of A baumannii bacteremia mortality $(24,31)$. Furthermore, APACHE II score, SOFA score, and inadequate empirical antibiotic therapy have been identified as prognostic factors for ventilator-associated A baumannii pneumonia mortality $(32,33)$. Additionally, age and acute renal 
failure have been identified as mortality predictors of multiresistant gram-negative bacteria infections(34) and thrombocytopenia as predictor of mortality in ICU patients.

\section{CONCLUSION}

With the increase of extended-spectrum antimicrobial application, $\mathrm{AB}$ is rapidly evolving toward multidrug resistance. In our study multidrug resistance $\mathrm{AB}$ rate was high. Nosocomial infections caused by AB are very difficult to treat. $\mathrm{AB}$ infections are associated with high high morbidity and mortality rate.Knowing the risk factors that indicate mortality in such patients and ensuring early diagnosis are of critical importance with respect to prognosis. Starting appropriate therapy by making the right decisions regarding the severity of acute and underlying conditions will have favorable effects on the management of A. baumannii bacteremia.

In conclusion, the risk factors that indicate mortality in patients and these patients are closely watched and bacterial early determination of the importance of the prognosis of the patient bears. Severe acute illness and underlying disease start appropriate treatment by making the right decision, the effect will be better in the A. baumannii bacteria. Also avoid unnecessary antibiotic treatment and prophylaxis and can be controlled as strict infection control measures abolition of risk factors, originating from A. Baumannii reduce possible bactericides and related deaths.

\section{REFERENCES}

1. Del Mar Tomas M, Cartelle M, Pertega S, Beceiro A, Llinares P, Canle D, Molina F, Villanueva R, Cisneros JM, Bou G. Hospital outbreak caused by a carbapenem-resistant strain of Acinetobacter baumannii: patient prognosis and risk factors for colonisation and infection. Clin Microbiol Infect 2005;11: 540-546.

2. Dettori M, Piana A, Deriu MG, Lo Curto P, Cossu A, Musumeci R, Cocuzza C, Astone V, Contu MA, Sotgiu G . Outbreak of multidrug-resistant Acinetobacter baumannii in an intensive care unit. New Microbiol 2014; 37: 185- 191.

3. Ye D, Shan J, Huang Y, Li J, Li C, Liu X, He W, Li Y, Mao P. A gloves-associated outbreak of imipenemresistant Acinetobacter baumannii in an intensive care unit in Guangdong, China. BMC Infect Dis.2015; 15: 179.

4. Dalla-Costa LM, Coelho JM, Souza HA, Castro ME, Stier CJ, Bragagnolo KL, Rea-Neto A, PenteadoFilho SR, Livermore DM, Woodford N . Outbreak of carbapenem-resistant Acinetobacter baumannii producing the OXA-23 enzyme in Curitiba, Brazil. J Clin Microbiol 2003;41: 3403-3406.

5. Teo J, Lim TP, Hsu LY, Tan TY, Sasikala S, Hon PY, Kwa AL, Apisarnthanarak A .Extensively drugresistant Acinetobacter baumannii in a Thai hospital: a molecular epidemiologic analysis and identification of bactericidal Polymyxin B-based combinations. Antimicrob Resist Infect Control 2015;4:2.

6. Markogiannakis A, Fildisis G, Tsiplakou S, Ikonomidis A, Koutsoukou A, Pournaras S, Manolis EN, Baltopoulos G, Tsakris A .Cross-transmission of multidrug-resistant Acinetobacter baumannii clonal strains causing episodes of sepsis in a trauma intensive care unit. Infect Control Hosp Epidemiol 2008;29: 410-417.

7. Senok A, Garaween G, Raji A, Khubnani H, Kim Sing G, Shibl A . Genetic relatedness of clinical and environmental Acinetobacter baumanii isolates from an intensive care unit outbreak. J Infect Dev Ctries 2015;9: 665-669.

8. Huttner A, Harbarth S, Carlet J, Cosgrove S, Goossens H, Holmes A, Jarlier V, Voss A, Pittet D. Antimicrobial resistance: a global view from the 2013 World Healthcare-Associated Infections Forum. Antimicrob Resist Infect Control. 2013;2:2-31.

9. Samuel S, Kayode O, Musa O, Nwigwe G, Aboderin A, Salami T, Taiwo S. Nosocomial infections and the challenges of control in developing countries. Afr J Clin Exp Microbiol. 2010;11:102-9.

10. Hasanin A, Eladawy A, Mohamed H, Salah Y, Lotfy A, Mostafa H, Ghaith D, Mukhtar A. Prevalence of extensively drug-resistant gram negative bacilli in surgical intensive care in Egypt. Pan Afr Med J. 
$2014 ; 19: 177,4307$.

11. Higgins PG, Dammhayn C, Hackel M, Seifert H. Global spread of carbapenem-resistant A. baumannii. Br Soc Antimicrob Chemother. 2010;428.

12. Chang YJ, Yeh ML, Li YC, Hsu CY, Lin CC, Hsu M-S, Chiu WT. Predicting hospital-acquired infections by scoring system with simple parameters. PLoS One. 2011;6:1-11.

13. Simonetti AF, Viasus D, Garcia-Vidal C, Carratalà J. Management of community-acquired pneumonia in older adults. Ther Adv Infect Dis. 2014;2:3-16.

14. Hill R, Paulus S, Dey P, Hurley MA, Carter B. Is undernutrition prognostic of infection complications in children undergoing surgery? A systematic review. J Hosp Infect. 2016;93:12-21.

15. Gyansa-Lutterodt M, Afriyie D, Asare G, Amponsah S, Abutiate H, Darko D. Antimicrobial use and susceptibility pattern of uropathogens associated with urinary tract infections at the Ghana Police Hospital. Glob J Pharmacol. 2014;8:306-15

16. Ghaith DM, Hassan RM, Hasanin AM. Rapid identifcation of nosocomial A. baumannii isolated from a surgical intensive care unit in Egypt. Ann Saudi Med. 2015;36(5):440-4.

17. Hasanin A, Mukhtar A, El-Adawy A, Elazizi H, Lotfyn A, Nassar H, Ghaith D. Ventilator associated pneumonia caused by extensive-drug resistant Acinetobacter species: colistin is the remaining choice. Egypt J Anaesth. 2016; 3-4

18. Lee HY, Chen CL, Wu SR, Huang CW, Chiu CH. Risk factors and outcome analysis of Acinetobacter baumannii complex bacteremia in critical patients. Crit Care Med 2014;42:1081-1088.

19. Falagas ME, Kopterides P. Risk factors for the isolation of multi-drug-resistant Acinetobacter baumannii and Pseudomonas aeruginosa: a systematic review of the literature. J Hosp Infect 2006; 64:7-15.

20. Zhou HY, Yuan Z, Du YP. Prior use of four invasive procedures increases the risk of Acinetobacter baumannii nosocomial bacteremia among patients in intensive care units: a systematic review and metaanalysis. Int J Infect Dis 2014;22:25-30.

21. Katsaragakis S, Markogiannakis H, Samara E, et al. predictors of mortality of Acinetobacter baumannii infections: A 2-year prospective study in a Greek surgical intensive care unit. Am J Infect Control 2010; 38: 631-5.

22. Prates CG, Martıns AF,Supertı SV, Lopes FS, Ramos F, Cantarellı VV, et al. Risk factors for 30-day mortality in patients with carbapenem-resistant Acinetobacter baumannii during an outbreak in an intensive care unit. Epidemiol Infect 2011;139:411-8

23. Seifert H, Strate A, Pulverer G. Nosocomial bacteremia due to Acinetobacter baumannii: clinical features, epidemiology, and predictors of mortality. Medicine (Baltimore) 1995;74:340-9.

24. Cisneros JM, Reyes MJ, Pacho’n J, Becerril B, Caballero FJ, Garcı'aGarmendı́a JL, et al. Bacteremia due to Acinetobacter baumannii: epidemiology, clinical findings, and prognostic features. Clin Infect Dis 1996; 22:1026-32.

25. Lortholary O, Fagon JY, Hoi AB, Slama MA, Pierre J, Giral P, et al. Nosocomial acquisition of multiresistant Acinetobacter baumannii: risk factors and prognosis. Clin Infect Dis 1995; 20:790-6.

25. Go'mez J, Simarro E, Ban os V, Requena L, Ruiz J, Garc1'a F, et al. Sixyear prospective study of risk and prognostic factors in patients with nosocomial sepsis caused by Acinetobacter baumannii. Eur J Clin Microbiol Infect Dis 1999; 18: 358-61.

27. Cisneros JM, Rodriguez-Ban o J. Nosocomial bacteremia due to Acinetobacter baumannii: epidemiology, clinical features and treatment. Clin Microbiol Infect 2002;8:687-93. 
28. Reina R, Estenssoro E, Sa'enz G, Canales HS, Gonzalvo R, Vidal G, et al. Safety and efficacy of colistin in Acinetobacter and Pseudomonas infections: a prospective cohort study. Intensive Care Med 2005; 31: 1058-65.

29. Chen HP, Chen TL, Lai CH, Fung CP, Wong WW, Yu KW, et al. Predictors of mortality in Acinetobacter baumannii bacteremia. J Microbiol Immunol Infect 2005;38:127-36.

30. del Mar Tomas M, Cartelle M, Pertega S, Beceiro A, Llinares P, Canle D, et al. Hospital outbreak caused by a carbapenem-resistant strain of Acinetobacter baumannii: patient prognosis and risk factors for colonisation and infection. Clin Microbiol Infect 2005;11:540-6.

31. Choi JY, Park YS, Kim CO, Park YS, Yoon HJ, Shin SY, et al. Mortality risk factors of Acinetobacter baumannii bacteraemia. Intern Med J 2005; 35:599-603.

32. Garnacho-Montero J, Ortiz-Leyba C, Ferna'ndez-Hinojosa E, Aldabo'- Palla's T, Cayuela A, MarquezVa'caro JA, et al. Acinetobacter baumannii ventilator-associated pneumonia: epidemiological and clinical findings. Intensive Care Med 2005; 31:649-55.

33. Kaul R, Burt JA, Cork L, Dedier H, Garcia M, Kennedy C, et al. Investigation of a multiyear multiple critical care unit outbreak due to relatively drug-sensitive Acinetobacter baumannii: risk factors and attributable mortality. J Infect Dis 1996; 174:1279-87.

34. Michalopoulos AS, Tsiodras S, Rellos K, Mentzelopoulos S, Falagas ME. Colistin treatment in patients with ICU-acquired infections caused by multiresistant gram-negative bacteria: the renaissance of an old antibiotic. Clin Microbiol Infect 2005; 11:115-21.

25. Vanderschueren S, De Weerdt A, Malbrain M, Vankersschaever D, Frans E, Wilmer A, et al. Thrombocytopenia and prognosis in intensive care. Crit Care Med 2000; 28:1871-6.

\section{Hosted file}

20452-TKDC-table1 (1).pdf available at https://authorea.com/users/383225/articles/499135-

multidrug-resistant-acinetobacter-baumannii-infections-in-a-cardiovascular-surgery-

intensive-care-unit-risk-factors-and-outcome-predictors 